\title{
A fresh start
}

\author{
Bhavin Jankharia \\ Editor-in-Chief, Indian Journal of Radiology and Imaging, Bhaveshwar Vihar, 383 Sardar V P Rd, Prarthana Samaj, \\ Mumbai - 400 004, India
}

Correspondence: Dr. Bhavin Jankharia, Editor-in-Chief, Indian Journal of Radiology and Imaging, Bhaveshwar Vihar, 383 Sardar VP Road, Prarthana Samaj, Mumbai - 400 004, India. E-mail: editor@ijri.org

Dear friends, colleagues and seniors

At the outset, I would like to thank all of you for giving me this opportunity to be the "Editor-in-Chief" of the Indian Journal of Radiology and Imaging (IJRI). I am honored and overwhelmed at the support that I have received so far.

I also apologize for the delay in bringing out this issue as well as the next (May 2007) one. We have had to start from scratch, with nothing but about 20 articles handed over to us from the previous years. Except for one radiology quiz, each and every article published in this issue, has been written after Dec 2006 and has been processed in the interim period (reviewed, revised, accepted and proofed). I would like to thank all the reviewers, editorial board members and the people at Medknow, specifically Dr. D. K. Sahu, who have made this possible.

We hope to bring out a mini-symposium with each issue. This issue's theme is cardiac CT, which has been guestedited by Dr. Hemant Telkar. The next issue's theme is cardiac MRI, followed by musculoskeletal USG in August 2007 and tuberculosis in November 2007. Any article pertaining to these subjects will be fast-tracked, if it has merit. Authors are encouraged to send in articles related to these subjects.

In subsequent editorials, I will also go about explaining the entire process of publication from the time we receive an article till the time it comes to print. It is an involved and laborious process requiring inputs from many people along the way. Medknow Publications has taken away the pain from this process with an amazing and extremely simple online system, which authors and reviewers have embraced with delight. Since January 2007, we have switched completely to this online system for article processing; from submissions to reviews to revisions to proofs.

Reviewers are the backbone of any journal. Prompt and good reviews help us in deciding which articles have merit and which don't and also give the authors and us the inputs necessary for improving the quality of the submitted articles.
We have already expanded our reviewer base significantly with reviewers from all over the world. Those who would like to be part of the reviewing process are requested to sign up at www.ijri.org.

Because of their presence on the board, members of the editorial board have a larger responsibility in ensuring that their reviews come in on time and that they participate in other aspects of the journal enthusiastically. Virtually all the members of the editorial board from last year have graciously accepted to continue, along with a few new additional members. I would like to welcome all of them to the IJRI fold.

If reviewers are important, authors are more so. Without articles, there is no journal. There has been a tendency in recent years to focus on case reports and quizzes. Our stand on case reports is very clear; unless the case report states an exceptional fact, it will most likely not be accepted. The same goes for quizzes, signs and images. The journal has to have more substance and original articles, review articles, pictorial essays, etc. will always be preferred.

Starting with this issue, we have a new section titled "Computers in Radiology". Dr. Indrajit and his colleagues will be discussing different aspects of the use of computers and technology in radiology. This issue's subject is "DICOM".

The radiology quiz has also undergone a change and will function as an actual quiz. There will be two quizzes in each issue, posed as questions and the answers will be published in the next issue. Readers are requested to send in their answers to quiz@ijri.org, stating the quiz name and the answer. Please do not give a differential diagnosis. The last date for submission of answers to this issue's quizzes, is June 15, 2007. The names of those who have answered correctly will be posted in the subsequent issue with the quiz answers. At the end of the year, those with the maximum correct answers will be given a special mention.

In subsequent issues, we plan to introduce many new 
sections. If you have any ideas, please email me at editor@ ijri.org.

All this has been possible only because of the immense and unstinting help from the core team; Dr. Sanjay Jain - Jt Editor and Secretary and Drs. Sanjeev Mani and I K Indrajit - Associate Editors as well as Shamina Petiwala - the journal secretary.

At the end, I would also like to bring to an end a controversy that doesn't seem to want to die down, regarding the "indexed" status of the IJRI. Though many authorities around the world "index" the contents of a journal (even
Google has started doing this), as far as the academic fraternity is concerned, being indexed means only one thing - having a listing in "Index Medicus" or in "Pubmed", run by the National Library of Medicine. Unfortunately, we are currently not indexed by NLM, though a few entities, such as Medlars (an Indian Government service), WHO-South East Asia and Google have started listing our contents. I hope that in my tenure we are able to get indexed by the National Library of Medicine.

I hope that all of you will support the journal to your utmost ability and help us make it a publication that radiologists think is worth reading. 